\title{
Airway complications in pediatric patients with congenital heart disease
}

\author{
lemets R., Yemets H., Zhovnir V., Ukrainian Children's Cardiac Center, Dept. of \\ Anaesthesiology \& Intensive Care, Kyiv, Ukraine
}

Airways complications in operated children with congenital heart disease (CHD) lead to serious difficulties in anaesthetic management and postoperative intensive care. Approximately $50 \%-60 \%$ of patients with CHD have different types of airways complications. This can lead to prolonged mechanical lung ventilation, time of intensive care unit (ICU) stay and increase treatment costs. We performed retrospective study of 8-year experience of management of patients with CHD, complicated by airway problems (compressions, malacia). The main goal was to reveal it's prevalence and to improve treatment results of the patients with CHD.

During 2008-2015 there were operated 8726 children with CHD in our clinic. From this group we separated patients with airways obstructions (study group) detected with the fiber-optic bronchoscopy before, during or after performed cardiac surgery. The indications for fibrobronchoscopy in children with CHD were diagnostic and therapeutic. In study group we estimated the presence and severity of airways compression or tracheobrochomalacia. Patients from the study group were compared with the ones that had not airway complications (control group). Demographic data, time of mechanical ventilation and ICU stay, 30-day mortality were calculated as the median and compared with Mann-Whitney U test.

Table 1. CHD distribution in study group

\begin{tabular}{|l|l|}
\hline Diagnosis & $\mathrm{n} /(\%)$ \\
\hline $\begin{array}{l}\text { Aortic arch anomaly (coarctation, interruption, } \\
\text { hypoplasy) }\end{array}$ & $38 /(37)$ \\
\hline $\begin{array}{l}\text { CHD with pulmonary hypertension (ventricular } \\
\text { septal defect, pulmonary valve absence syndrome } \\
\text { etc.) }\end{array}$ & $18 /(18)$ \\
\hline $\begin{array}{l}\text { Vascular ring (double aortic arch, pulmonary slings, } \\
\text { right aortic arch with aberrant subclavian artery } \\
\text { etc.) }\end{array}$ & $27 /(26)$ \\
\hline Other CHD's & $20 /(19)$ \\
\hline Total & 103 \\
\hline
\end{tabular}

Study group consisted of 103 patients, who had disorder of airway patency. They represented $1,4 \%$ off all our operated patients. The median age was 6,2 months, median weight was $5,6 \mathrm{~kg}$. Perioperative and anaesthetic management of these patients was performed considering their condition and cardiac disease.
Fiber-optic examination was performed with $2.8 \mathrm{~mm}$ bronchoscope, in 16 patients (16\% patients in study group) before cardiac surgery and the other 87 patients (84\%) was examined during operation. All fibrobronchoscopies in study group were performed with general anesthesia.

71 patients $(69 \%)$ had different degree of trachea or bronchi narrowing. 32 patients $(31 \%)$ had different degree of tracheobronchomalacia. In 17 patients we performed aortopexy or pulmonary artery-pexy. These patients had significant airways narrowing (more than $50 \%$ of airway lumen). In 8 cases it was difficult to wean them from mechanical ventilation.

Control group consisted of 8623 patients $(98,6 \%)$ without concomitant problems of airways during perioperative period. Median time of ICU stay in study group was 12 days, whereas in control group it was 3 days $(p<0,05)$. Median time of respiratory support for study group was 68 hours, that was significantly longer then analogous time in control group (patients without airway narrowing) - 11 hours $(p<0,05)$. The 30 days mortality rate in study group was $7,7 \%$, while this rate for all pediatric patients operated last 8 years in our clinic was $1,4 \%(\mathrm{p}<0,05)$.

4-months old patient with compression of right main bronchus with CHD (VSD, vascular ring): picture1 - before cardiac surgery, picture 2 - after cardiac surgery

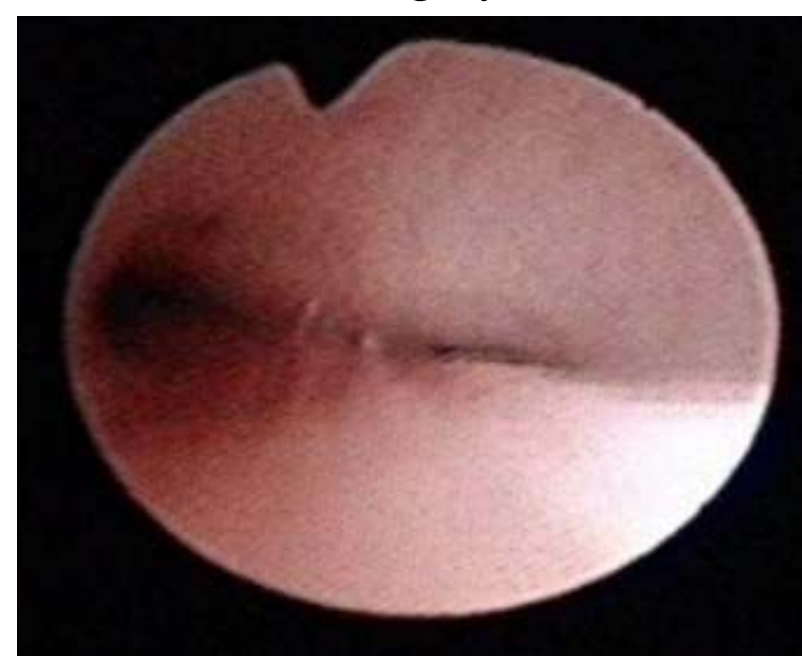

Picture 1.

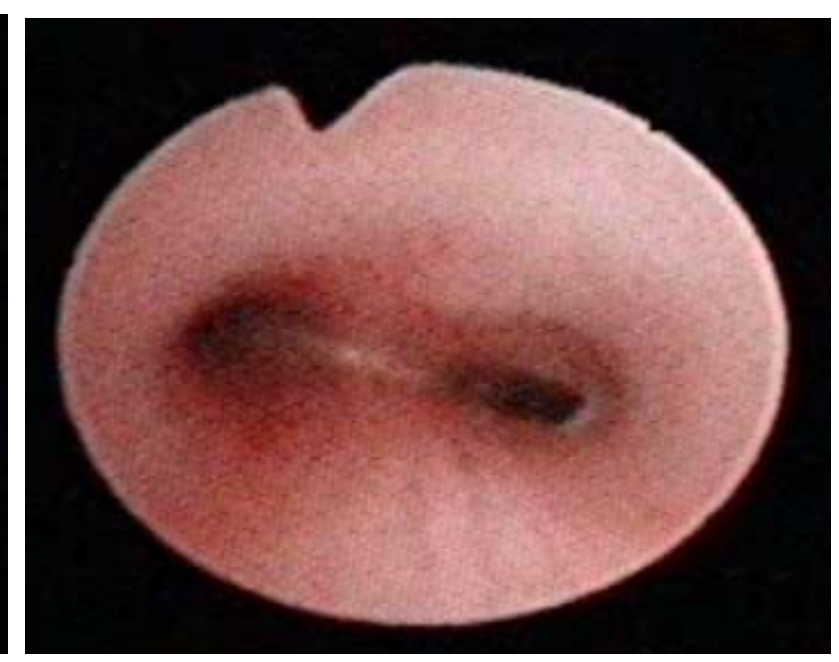

Picture 2.
Airways compressions and tracheobronchomalacia in patients with CHD can complicate postoperative period significantly. Airways complications lead to prolonged time of mechanical ventilation and time of ICU stay. Fiber-optic examination of the airways can be useful in selected cases. Our position is to provide more accurate respiratory system assessment of patients with expected concomitant airways compressions.

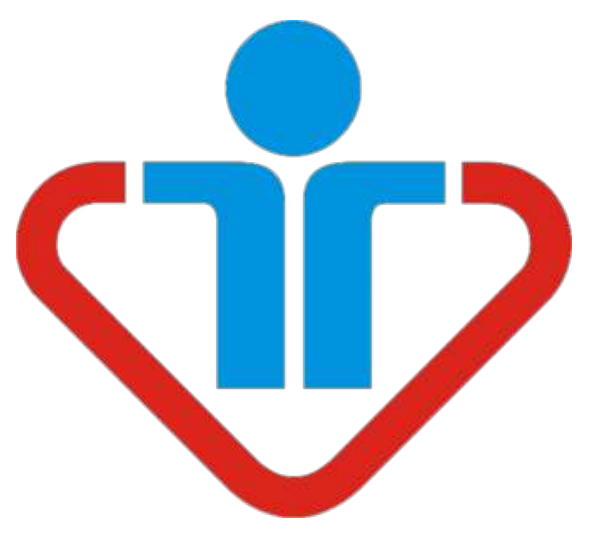

